\title{
NAKAMURA, Eunice. Depressão na infância: uma abordagem antropológica. São Paulo: Hucitec: Fapesp, 2016. 286 p.
}

Flávia Ferreira Pires ${ }^{*}$

*Universidade Federal da Paraíba - João Pessoa, PB, Brasil ffp23279@gmail.com 
Eunice Nakamura, professora da Unifesp em Santos, no campus Baixada Santista, é autora do livro Depressão na infância: uma abordagem antropológica, de 286 páginas, publicado em 2016 pela editora Hucitec, através de recursos da Fapesp. Trata-se do texto da tese de doutorado da autora defendida em 2004, na Faculdade de Filosofia, Letras e Ciências Humanas da Universidade de São Paulo sob título homônimo.

O objetivo geral da pesquisa é compreender o processo de disseminação e banalização da depressão infantil, atualmente verificado na sociedade, a partir dos aspectos e mecanismos socioculturais nele envolvidos. Tomando como ponto de partida a noção elaborada no discurso médico-científico, associada à doença, busca-se apreender outras representações de depressão infantil e seus significados, em contextos específicos. (p. 32).

Como não podia deixar de ser, a autora justifica a publicação do texto da tese 13 anos após a sua defesa na "Apresentação". Por que agora? No final dos anos 1990 a depressão infantil começava a ser debatida majoritariamente em estudos da área médica. Do ponto de vista socioantropológico a pesquisa era muito incipiente. Hoje, no entanto, pesquisar o tema tornou-se um imperativo social tendo em vista o aumento das taxas de depressão especialmente na população infantil, mas também na população adulta. A OMS aponta uma "prevalência mundial de problemas mentais na infância e adolescência de aproximadamente 20\%" (p. 21). Esse aumento no diagnóstico da depressão coincidiu com uma crescente atenção da academia.

É no capítulo 1, "Depressão infantil: uma abordagem antropológica”, que a autora assinala alguns estudos feitos depois da defesa da tese que estão em sintonia com o livro, ou seja, tratam a doença de um ponto de vista socioantropológico, embora ressalte a escassez de literatura sobre o tema na antropologia médica e na própria área médica ainda nos dias de hoje, o que convida a uma perspectiva crítica e faz do livro uma contribuição salutar e necessária.

Eunice Nakamura apresenta a ideia geral do livro ao afirmar que embora tratada de um ponto de vista universal - aquele do discurso médico-científico -, a compreensão da depressão infantil só pode ser feita se levarmos em conta as diferentes visões de mundo sobre doença mental e infância. A pesquisa que embasa o livro analisou os discursos 1) médico-científico veiculados na 
imprensa; 2) dos profissionais de saúde (especialmente, médicos psiquiatras do Serviço de Psiquiatria da Infância e Adolescência - Sepia do Hospital das Clínicas da Faculdade de Medicina da Universidade de São Paulo); e 3) das famílias com crianças de 6 a 12 anos com diagnóstico de depressão.

Nota-se, todavia, que o discurso das crianças não foi objeto de investigação, o que representa um limite do ponto de vista teórico-metodológico. Afirma-se que "[...] a depressão infantil apresenta-se como uma doença cujos sintomas e critérios de diagnósticos são [...] referidos em geral à depressão em adultos" (p. 40). Algo parecido podemos afirmar sobre o conhecimento antropológico mainstream que sofre do que temos chamado, no campo da antropologia da criança, de "adultocentrismo".

Do ponto de vista metodológico, apresentado no capítulo 2, "Métodos e técnicas de pesquisa", trata-se de um trabalho etnográfico, ressaltando que há um foco nos discursos. Como técnicas de coleta de dados, utilizou-se de análise documental, entrevistas e observações. O serviço de saúde observado fica localizado na área central de São Paulo e as famílias pesquisadas moram nas periferias da cidade (um mapa de localização das famílias entrevistadas está disponível na página 92). Eunice Nakamura chama a atenção para o "fenômeno da depressão infantil num contexto atual e bastante familiar, em especial para as classes populares, marcado por necessidades e insatisfações relacionadas a condições socioeconômicas, afetivas e emocionais instáveis, e no geral, contraditórias" (p. 36), o que coloca desafios importantes para o diagnóstico e tratamento da doença (capítulo 6, "O lugar da depressão infantil na realidade").

Um processo de banalização da noção médico-científica de depressão infantil se dá através da simplificação do conceito médico-científico da doença em função da associação a ideias difundidas pela mídia e pelo senso comum. Esse é o foco do capítulo 3, "O processo de banalização da noção médico-científica de depressão infantil”. No entanto, se a imprensa sugere uma naturalização do discurso que lhe deu origem, o mesmo não ocorre com a população. São apresentados os discursos elaborados pelos profissionais de saúde, médicos psiquiatras vinculados ao Sepia e os discursos das famílias das crianças acompanhadas pelo serviço. Ao contrário da noção banalizada médico-científica e difundida pela mídia, os discursos das famílias apontam que as doenças devem ser vistas em relação às suas representações e manifestam outras noções de depressão infantil, como é apresentado no capítulo 4, “Discursos sobre depressão infantil”. 
São apresentados modelos explicativos que visam melhor compreender os diferentes discursos e noções de depressão infantil no capítulo 5, "Um modelo explicativo do fenômeno da depressão infantil". Ao mesmo tempo em que vemos um uso indiscriminado do rótulo da doença, proliferam significados e estratégias para explicar o fenômeno. A autora analisa as estruturas inconscientes que informam esses modelos. Fala-se de noção médico-científica, noção banalizada (imprensa), noção das famílias entrevistadas, noção dos profissionais de saúde entrevistados.

Para ir finalizando, o livro também é composto pelos textos da orelha esquerda, da quarta capa, do prefácio e do posfácio.

O “Prefácio", assinado por José Francisco Quirino dos Santos, professor aposentado da Universidade de São Paulo, com trajetória reconhecida na antropologia médica, destaca a qualidade da pesquisa bibliográfica e das entrevistas realizadas, afirmando que o livro é um "verdadeiro presente ao leitor interessado", que "pode ser egresso das ciências humanas, ou formado pelas exatas" (p. 17). Para ele, o livro contribui para o aprimoramento do conhecimento em torno da depressão infantil.

A orelha esquerda é assinada por Clarice Cohn (UFSCar), antropóloga que se destaca nas áreas de etnologia e antropologia da criança, enfatiza a contribuição do livro para as discussões sobre as noções de infância que informam a busca por diagnóstico e cura da depressão infantil por parte das famílias, além de definir as práticas médicas. Nesse sentido, além da contribuição à antropologia da saúde, o livro também é uma contribuição à antropologia da criança ou da infância.

A quarta capa, de Aurea Ianni, professora livre-docente da Faculdade de Saúde Pública da Universidade de São Paulo, conhecida pela sua trajetória de pesquisa na interface das ciências sociais e da saúde, põe em relevo que a compreensão do sofrimento mental muitas vezes fica restrita aos serviços de saúde. O livro, no entanto, "busca compreender o fenômeno da depressão para além dos discursos médico e adulto [...]", embora, eu acrescentaria, as crianças não sejam propriamente sujeitos da pesquisa.

Um esforço de síntese é feito ao final do livro, nas "Considerações finais". Eunice Nakamura afirma que "a ocorrência da depressão infantil parece revelar-se, assim, como um mecanismo sociocultural pela qual a sociedade busca responder aos momentos de crise e de dúvidas, apresentando novas estratégias 
para preservar sua própria ordem" (p. 260). No entanto, é na etnografia, em contato com médicos e famílias que a pesquisa se destaca, envolvendo o leitor e trazendo uma verdadeira contribuição para a antropologia. As noções de depressão infantil das famílias não remetem à de doença, mas são complementares às noções dos profissionais da saúde na medida em que veem efetividade do tratamento, principalmente medicamentoso. É preciso levar a sério esses dados para um aprimoramento no atendimento aos pacientes e suas famílias.

Não resta dúvidas de que se trata de uma importante contribuição à antropologia da infância na medida em que nos presenteia como esmiuçamento de uma noção de infância localizada e pouco conhecida, que dirige a conduta de pais e médicos e a própria abordagem midiática. Incluir as crianças mesmas como interlocutoras, portadoras ou não da doença, para pensar a depressão na infância de uma abordagem antropológica demanda um esforço continuado de pesquisa. É justamente essa direção que aponta o "Posfácio", através da sinalização de investimentos de pesquisa nas áreas da antropologia médica e antropologia da criança, através de projetos futuros. São notícias alvissareiras cujos frutos estamos ansiosamente aguardando. 